\title{
Development of Optimal Breeding Pigs Using DNA Marker Information
}

\author{
Sang-Wook Kim ${ }^{1}$, Jung-Gun Roh', Yang-ll Cho', \\ Bong-Hwan Choi ${ }^{2}$, Tae-Hun $\mathrm{Kim}^{2}$, Jong-Joo $\mathrm{Kim}^{3}$ \\ and Kwan Suk Kim ${ }^{1 *}$
}

${ }^{1}$ Department of Animal Science, Chungbuk National University, Cheongju 361-763, Korea, ${ }^{2}$ National Institute of Animal Science, Suwon 441-706, Korea, ${ }^{3}$ School of Biotechnology, Yeungnam University, Gyeongsan 705030, Korea

\begin{abstract}
The aim of the study was to investigate pig reference families, generated from Korean native pigs (KNP) that were crossed with Yorkshire (YS) breeds, which were used to evaluate genetic markers to select breeding animals with superior pork quality. A set of five candidate genes (PRKAG3, MC4R, CAST, ESR, and PRLR) was analyzed for association with pork quality traits. PRKAG3 (1199V) SNP genotypes were significantly associated with muscle moisture, protein, and fat contents. The MC4R D298N polymorphism was significantly associated with meat tenderness and color traits. The CAST polymorphism was significantly associated with muscle moisture and crude protein traits. These three genes have been associated with pork quality traits in other pig populations, and some of our results are consistent with earlier studies. In addition, two reproductive candidate genes (ESR and $P R L R$ ) did not have significant associations. These results suggest that further study is warranted to investigate and develop more DNA markers associated with pork quality in our KNP-crossed pig families.
\end{abstract}

Keywords: major gene, single nucleotide polymorphism, meat quality, pig breeding

\section{Introduction}

Livestock genome research has evolved remarkably for identifying molecular mechanisms underlying quantitative traits, such as growth performance and meat quality. Animal breeders and geneticists now explore genomics to obtain and to use molecular genetic information in

*Corresponding author: E-mail kwanskim@chungbuk.ac.kr Tel +82-43-261-2547, Fax +82-43-273-2240

Accepted 1 June 2010 selection programs for superior animals with desirable phenotypes. With the consumer' $s$ interest in the quality and safety of meat products, the genetic control of pork quality traits has become important in the swine industry. However, meat quality traits are measured only after the slaughter process, so the animals that are proven to have superior meat quality are not able to used directly for breeding programs. DNA marker technology enables the pig breeder to monitor and predict the molecular breeding value of the meat quality without slaughtering animals.

For identification of genetic loci or DNA markers affecting pork quality, many reference pig families were generated and then analyzed for association between pork quality phenotypes and genotypes (Rothschild et al., 2007). A substantial number of candidate genes have shown significant associations with many traits important to swine production. Two biological candidate genes (ESR and PRLR) have shown significant association with litter size (Short et al., 1997; Tomas et al., 2006). An MC4R mutation has shown a significant reduction in feed intake with less fat deposition (Kim et al., 2000a; Kim et al., 2004). Additional important genes, PRKAG3 and CAST, have been shown to be associated with changes in $\mathrm{pH}$ and tenderness (Ernst et al., 1998; Ciobanu et al., 2001). Therefore, in this study, genotyping and association analyses of 5 SNPs in the aforementioned genes were investigated in pig reference families generated from Korean native pig (KNP)-crossed Yorkshire (YS) breeds, with the objective to evaluate KNP $\mathrm{x}$ YS families as a reference population for exploring and identifying genetic markers to select breeding animals with superior pork quality and to understand genomic mechanisms underlying pork quality variation between KNP and YS.

\section{Methods}

\section{Animals}

A three-generation resource population was developed from reciprocal crosses between the Korean native pig (KNP) and Yorkshire (YS) breeds at Chungbuk National University. The F1 crossbreeds were produced from two purebred KNP boars crossed with five purebred YS sows (F1: KY) as well as three purebred $Y S$ boars crossed with 14 purebred KNP sows (F1: YK). Randomly selected $\mathrm{F} 1$ crossbreds mated to produce $\mathrm{F} 2$ animals 
using the following three mating systems: 1) $11 \mathrm{YK}$ boars were intercrossed with $46 \mathrm{YK}$ sows ( $\mathrm{YK} \times \mathrm{YK})$; 2) $5 \mathrm{KY}$ boars were intercrossed with $19 \mathrm{KY}$ sows $(\mathrm{KY} \times \mathrm{KY})$; and 3) $5 \mathrm{KY}$ boars were intercrossed with 7 $Y K$ sows $(K Y \times Y K)$. The $F 2$ pigs were raised under the same feeding and management practices, and in total, 750 pigs were performance-tested and 349 randomly selected pigs were slaughtered at age 190 240 days (90 $110 \mathrm{~kg}$ live weight) to assess the meat quality

Table 1. Means and standard deviation of traits measured in pork from $\mathrm{F} 2$ Korean native pig $\mathrm{x}$ Yorkshire

\begin{tabular}{lrr}
\hline & Mean & SD \\
\hline Chemical composition (\%) & \\
Moisture & 73.96 & 1.71 \\
Protein & 22.18 & 1.59 \\
Fat & 2.49 & 1.45 \\
Ash & 1.05 & 0.13 \\
Meat quality characteristics & & \\
Water-holding capacity (\%) & 58.03 & 6.34 \\
24-h pH & 5.63 & 0.25 \\
Drip loss (\%) & 5.11 & 1.81 \\
Cooking loss (\%) & 32.26 & 3.53 \\
Shear force (kg) & 1.73 & 0.43 \\
Lightness (Hunter L*) & 52.69 & 5.50 \\
Redness (Hunter a*) & 5.72 & 2.03 \\
Yellowness (Hunter b*) & 7.43 & 1.80 \\
Cholesterol (mg/100g) & 142.02 & 84.38 \\
Subjective evaluation* & & \\
Marbling & 2.39 & 1.01 \\
Color & 3.06 & 0.49 \\
Texture & 2.86 & 0.42 \\
Total acceptability & 2.91 & 0.30 \\
\hline
\end{tabular}

*Marbring, 1: extremely low in intramuscular fat, 5: very abundant in intramuscular fat. Texture, 1: extremely bad in texture, 5: very good in texture. Meat color, 1: very pale, 5: very dark. Total acceptability, 1: extremely undesirable, 5: extremely desirable traits.

\section{Phenotypes}

The meat quality traits included crude ash (Cash), crude protein (Cpro), crude lipid (intramuscular fat, IMF), drip loss (DL), water holding capacity (WHC), moisture, cooking loss (CL), shear force (shearforce), $\mathrm{pH}$ at $24 \mathrm{hrs}$ $(\mathrm{pH})$, color score, marbling score, tenderness, juiciness, flavor, and total cholesterol (Table 1). These traits were measured according to standard methods (Oh et al., 2008).

\section{SNP genotyping}

A total of 5 candidate gene polymorphisms were previously reported, and detailed information about these SNPs and their respective PCR_RFLP genotyping approaches is illustrated in Table 2. Polymerase chain reactions were performed in $10-\mu \mathrm{l}$ volumes, containing $12 \mathrm{ng}$ of genomic DNA, $10 \mathrm{pmol}$ of each primer, $200 \mu \mathrm{M}$ of each dNTP, 2.5 units of Taq DNA polymerase (Solgent, Korea), and reaction buffer with $1.5 \mathrm{mM}$ $\mathrm{MgCl}_{2}$. The thermocycling reaction was performed in a PTC-200 thermocycler (MJ Research, Watertown, MA, USA) with a 10 -min initial denaturation at $95^{\circ} \mathrm{C}$; $40 \mathrm{cy}$ cles of $95^{\circ} \mathrm{C}$ for $30 \mathrm{~s}, 45 \sim 65^{\circ} \mathrm{C}$ for $30 \mathrm{~s}$, and $72^{\circ} \mathrm{C}$ for $40 \mathrm{~s}$; and a final extension at $72^{\circ} \mathrm{C}$ for $5 \mathrm{~min}$. The result of the PCR reaction was identified by $2 \%$ agarose gel electrophoresis at $100 \mathrm{mV}$ for $20 \mathrm{~min}$. The information for each primer sequence, annealing temperature, and fragment size is given in Table 2. All restriction enzymes were supplied by New England BioLabs (Ipswich, MA, USA), and restriction digests were performed according to the manufacturer's recommendations. Digested PCR products were analyzed on $2.5 \sim 4 \%$ agarose gels, and each allele was scored manually. The restriction enzymes and polymorphic fragment sizes used for SNP genotyping are given in Table 2.

Table 2. PCR primers and restriction enzymes used for SNP genotyping

\begin{tabular}{|c|c|c|c|c|c|c|}
\hline Gene & $\begin{array}{l}\text { Primer sequences } \\
\qquad\left(5^{\prime} \rightarrow 3^{\prime}\right)\end{array}$ & $\begin{array}{l}\text { Fragment } \\
\text { size (bp) }\end{array}$ & $\begin{array}{l}\mathrm{T}_{\mathrm{A}} \\
\left({ }^{\circ} \mathrm{C}\right)\end{array}$ & $\begin{array}{l}\text { Restriction } \\
\text { enzyme }\end{array}$ & $\begin{array}{l}\text { Size (bp) of the allelic } \\
\text { polymorphism }\end{array}$ & Reference \\
\hline \multirow[t]{2}{*}{ PRKAG3 } & GGAGCAAATGTGCAGACAAG & 700 & 60 & BsaH I & 220,180 & Ciobanu et al (2001) \\
\hline & CCCACGAAGCTCTGCTTCTT & & & & & \\
\hline MC4R & TACCCTGACCATCTTGATTG & 226 & 62 & $\operatorname{Taq}^{Q} /$ & 156,70 & Kim et al (2000) \\
\hline \multirow[t]{2}{*}{ CAST } & $\begin{array}{l}\text { ATAGCAACAGATGATCTCTTTG } \\
\text { GCGTGCTCATAAAGAAAAAGC }\end{array}$ & 610 & 60 & Rsa I & 360,250 & Ernst et al (1998) \\
\hline & TGCAGATACACCAGTAACAG & & & & & \\
\hline ESR & $\begin{array}{l}\text { CCTGTTTTTACAGTGACTTTTACAGAG } \\
\text { CACTTCGAGGGTCAGTCCAATTAG }\end{array}$ & 120 & 55 & Pvu /I & 65,55 & Short et al (1997) \\
\hline PRLR & $\begin{array}{l}\text { CGTGGCTCCGTTTGAAGAACC } \\
\text { CTGAAAGGAGTGCATAAAGCC }\end{array}$ & 190 & 58 & Msc / & 113,77 & Tomas et al (2006) \\
\hline
\end{tabular}


Table 3. Genotype and minor allele frequency of 5 polymorphisms in five candidate genes genotyped in F2 Korean native pig $x$ Large white pigs

\begin{tabular}{|c|c|c|c|c|c|c|c|}
\hline Gene & \multicolumn{3}{|c|}{ Genotype (No. of animals) } & Total & Minor allele & Heterozygosity & HWE \\
\hline PRKAG3 & AA (6) $2 \%$ & AG (75) $22 \%$ & GG (266) $76 \%$ & 347 & 0.125 & 0.216 & 0.788 \\
\hline MC4R & AA (59) $18 \%$ & AG (177) 54\% & GG (88) $28 \%$ & 324 & 0.455 & 0.271 & 0.067 \\
\hline CAST & EE (186) 58\% & EF (108) 34\% & FF (23) $8 \%$ & 317 & 0.224 & 0.340 & 0.566 \\
\hline ESR & TT (127) $37 \%$ & TC (145) $42 \%$ & $\mathrm{CC}(71) 21 \%$ & 343 & 0.418 & 0.370 & 0.015 \\
\hline PRLR3 & GG (69) $20 \%$ & GA (173) $50 \%$ & AA (101) $30 \%$ & 343 & 0.453 & 0.294 & 0.744 \\
\hline
\end{tabular}

\section{Statistical analysis}

A goodness-of-fit chi-square test was used to test for Hardy-Weinberg equilibrium (HWE) by comparing the observed number of subjects for each genotype with the expected number of subjects, assuming HWE; genotype distributions were tested at each polymorphic locus for departure from HWE. A GLM procedure in SAS (Version 9.01; SAS, Inst., Inc., Cary, NC) was used to analyze the association of SNP marker genotypes of the 5 candidate gene polymorphisms with pork quality traits. The linear model used was as follows:

$$
\mathrm{Y}_{\mathrm{ijk}}=u+\mathrm{S}_{\mathrm{i}}+\mathrm{G}_{\mathrm{j}}+\mathrm{e}_{\mathrm{ijk}}
$$

where $Y_{i j k}$ is the observation for each trait, $u$ is the overall mean for each trait, $S_{i}$ is the fixed effect of sex, $G_{j}$ is the fixed effect of genotype, and eijk is the random residual effect.

\section{Results and Discussion}

\section{Phenotypic study}

The pig traits in this study were typical traits of economic importance to the pig industry, but they may have applications for human metabolic conditions. Table 1 lists the means and standard deviations of phenotypic variation of $350 \mathrm{~F} 2$ animals generated from KNPcrossed YS breeds. The meat quality characteristics were affected by lipid metabolism, insulin sensitivity, and muscle fiber types; thus, they certainly have implications for diabetes in humans (Tanner et al., 2002; He et al., 2001). There are clear genetic (or genomic) differences in the meat characteristics between KNP and YS breeds; thus, KNP- and YS-crossed F2 animals have expressed a large quantitative variation in these measured traits. It has been reported that KNP meat color has a significantly higher redness and yellowness than that of YS meat (Kim et al., 2008). Muscle-fat content (marbling or crude lipid) was also significantly higher in KNP animals, but water-holding capacity and $\mathrm{pH}$ were not significantly different between the two breeds (Kim et al., 2008).

\section{Genotypic frequencies of gene polymorphisms}

The distribution of genotypic and allelic frequencies for the analyzed SNPs is listed in Table 3. The PRKAG3 AA genotypic animals (199II) constituted only $2 \%$ in our pig families. The pig PRKAG3 gene I199V polymorphism was reported to have a greater effect on meat quality, but the "favorable" allele 199l was very low in most other pig breeds, except for the Berkshire pigs (Ciobanu et al., 2001; Huang et al., 2004).

The MC4R polymorphism (D298N) was quite polymorphic in the KNP $x$ YS F2 animals. Previous studies have shown that different pig breeds have a different distribution of genotype frequencies (Bruun et al., 2006; Kim et al., 2000b). Bruun et al. (2006) reported a significant increase in $298 \mathrm{~N}$ allele frequencies in Hampshire, Landrace, and Duroc with a selection program for growth rate. It was also reported that multiple variants of pig MC4R were identified, and their haplotypes might have originated differently among pig breeds (Fan et al., 2009).

The CAST, ESR, and PRLR gene polymorphisms existed in the KNP $x$ YS F2 animals. Several CAST polymorphisms were studied in Chinese Jinpi pigs and found to be completely linked in the Jinpi pigs $(\mathrm{Wu}$ et al., 2007).

\section{Association of genotypes with the phenotypes}

Association results at significance levels $(<0.05)$ are listed in Table 4. Based on the results, the PRKAG3 (I199V) SNP genotypes were significantly associated with muscle moisture, protein, and fat contents. The PRKAG3 AA genotype animals had more lipids in the muscle, and the muscle lipid content was negatively correlated with muscle moisture content. The PRKAG3 $\mathrm{AA}$ animals also had less drip loss, which means higher water-holding capacity. Our results are consistent with previous reports in which the AA genotype pigs had 
84 Genomics \& Informatics Vol. 8(2) 81-85, June 2010

Table 4. Association of 5 candidate gene polymorphism and phenotypic traits from F2 KNP $x$ YS pigs

\begin{tabular}{|c|c|c|c|c|c|}
\hline \multirow{2}{*}{ Gene } & \multirow{2}{*}{ Phenotypic trait } & \multicolumn{3}{|c|}{ Genotypic least squares means (SE) } & \multirow{2}{*}{ P-value } \\
\hline & & 11 & 12 & 22 & \\
\hline \multirow[t]{8}{*}{ PRKAG3 $(n=347)$} & Moisture (\%) & AA : $72.073(0.676)^{e}$ & AG : $73.238(0.191)^{e}$ & GG : $74.207(0.101)^{f}$ & $<0.0001$ \\
\hline & Crude protein (\%) & AA : $23.762(0.648)^{a}$ & AG : $22.410(0.18)^{b}$ & GG : $22.086(0.097)^{\mathrm{b}}$ & 0.0153 \\
\hline & Crude lipid (\%) & AA : $3.116(0.584)^{e, f}$ & AG : $3.027(0.165)^{\mathrm{e}}$ & GG : $2.333(0.088)^{\dagger}$ & 0.0007 \\
\hline & Drip loss (\%) & AA : $4.500(0.734)^{a, b}$ & AG : $5.556(0.207)^{a}$ & GG : $4.995(0.110)^{b}$ & 0.0422 \\
\hline & Marbling (\%) & AA: $3.258(0.393)^{a}$ & AG : $2.876(0.112)^{\mathrm{a}, \mathrm{e}}$ & GG : $2.238(0.059)^{f}$ & $<0.0001$ \\
\hline & Tenderness (TLD) & AA : $3.597(0.293)^{a}$ & AG : $3.185(0.083)^{a}$ & GG : $3.025(0.044)^{b}$ & 0.0467 \\
\hline & Lightness (CIE L) & AA : $56.730(2.220)^{\mathrm{a}}$ & $A G: 53.940(0.628)^{a}$ & GG : $52.241(0.333)^{b}$ & 0.0112 \\
\hline & Yellowness (CIE b) & AA : $9.306(0.725)^{a}$ & AG : $7.935(0.205)^{a}$ & $\mathrm{GG}: 7.250(0.108)^{\mathrm{e}}$ & 0.00005 \\
\hline \multirow[t]{3}{*}{ MC4R (n=324) } & Tenderness (TLD) & AA $: 2.851(0.094)^{a, b}$ & $A G: 3.120(0.054)^{a}$ & $\mathrm{GG}: 3.106(0.077)^{\mathrm{b}}$ & 0.0410 \\
\hline & Lightness (CIE L) & AA : $51.355(0.701)^{\mathrm{a}}$ & $A G: 53.217(0.404)^{b}$ & $\mathrm{GG}: 53.492(0.573)^{\mathrm{b}}$ & 0.0401 \\
\hline & Yellowness (CIE b) & AA : $6.945(0.231)^{\mathrm{a}}$ & $A G: 7.545(0.133)^{b}$ & $\mathrm{GG}: 7.842(0.189)^{\mathrm{b}}$ & 0.0114 \\
\hline \multirow[t]{2}{*}{ CAST $(n=317)$} & Moisture (\%) & $\mathrm{EE}: 73.693(0.126)^{\mathrm{c}}$ & $\mathrm{EF}: 74.299(0.167)^{\mathrm{d}}$ & FF :74.060 (0.360) ${ }^{\mathrm{d}}$ & 0.0151 \\
\hline & Crude protein (\%) & EE : $22.475(0.115)^{\mathrm{e}}$ & EF : $21.910(0.153)^{f}$ & FF : $21.895(0.329)^{f}$ & 0.0077 \\
\hline ESR $(n=343)$ & Marbling (\%) & $C C: 2.543(0.118)^{a}$ & TC : $2.545(0.083)^{a, c}$ & $T T: 2.165(0.088)^{c}$ & 0.0035 \\
\hline
\end{tabular}

Significance level: ${ }^{\mathrm{a}, \mathrm{b}} 0.05 ;{ }^{\mathrm{c}, \mathrm{d}} 0.01 ;{ }^{\mathrm{e}, \mathrm{f}} 0.005$.

darker meat color and higher $\mathrm{pH}$ and water-holding capacity (Ciobanu et al., 2001).

The MC4R D298N polymorphism was not associated with muscle lipid content in the KNP $x$ YS F2 animals, but the polymorphism was significantly associated with meat tenderness and color traits. The MC4R AA genotype animals were tender and darker than in the other genotype animals. Previous studies have found that MC4R D298N is associated with fatness and growth rate traits in many pig populations with different genetic backgrounds (Bruun et al., 2006; Houston et al., 2004; Hernandez-Sanchez et al., 2003; Meidtner et al., 2006). Unfortunately, we did not have the backfat thickness records to test if the MC4R D298N polymorphism was associated with fat deposition traits in KNP $x$ YS F2 animals, but it warrants the identification of the MC4R gene structure in KNP pigs to investigate the functional mechanisms of obesity-related phenotypes (Barb et al., 2010; Switonski et al., 2010).

The CAST Rsal polymorphism was associated with moisture and crude protein levels (Table 4). The CAST FF genotype was associated with less moisture and more crude protein in the muscle, and these results were similar with results in the Chinese Jinpi breed, in which the FF genotype was significantly higher in the muscle area (Wu et al., 2007). We did not find an association of tenderness with the Rsal CAST polymorphism, but almost 900 polymorphisms were detected in pig CAST gene sequences, and causative mutation(s) affecting pork tenderness might exist within the CAST gene (Meyers and Beever, 2008).

With regard to the $E S R$ and $P R L R$ gene polymorphisms, it was found that the ESR polymorphism was asso- ciated with marbling score, which is a subjective measurement of muscular fat level. No trait association was found with the PRLR polymorphism. It has been reported that the ESR Pvu II polymorphism is significantly associated with backfat thickness (Short et al., 1997).

From the present study, several gene polymorphisms that are known to be associated with pork quality traits were tested in KNP $x$ YS F2 animals. Several previous associations were confirmed, but it is suggested that the limited sample size of animals, different genetic backgrounds, and limited candidate genes that were studied might create some discrepancies from other studies. Our study did not investigate the possible interactions between the candidate gene polymorphisms due to the limited sample size of the animals. Therefore, additional work is warranted with more animals and gene polymorphisms to develop a selection program using DNA marker information.

\section{Acknowledgments}

This work was supported by a research grant of Chungbuk National University in 2008.

\section{References}

Barb, C.R., Hausman, G.J., Rekaya, R., Lents, C.A., Lkhagvadorj, S., Qu, L., Cai, W., Couture, O.P., Anderson, L.L., Dekkers, J.C., and Tuggle, C.K. (2010). Gene expression in hypothalamus, liver and adipose tissues and food intake response to melanocortin-4 receptor (MC4R) agonist in pigs expressing MC4R mutations. Physiol. Genomics DOI: 00006.2010 
Bruun, C.S., Jorgensen, C.B., Nielsen, V.H., Andersson, L., and Fredholm, M. (2006). Evaluation of the porcine melanocortin 4 receptor (MC4R) gene as a positional candidate for a fatness QTL in a cross between Landrace and Hampshire. Anim. Genet. 37, 359-362.

Ciobanu, D., Bastiaansen, J., Malek, M., Helm, J., Woollard, J., Plastow, G., and Rothschild, M. (2001). Evidence for new alleles in the protein kinase adenosine monophosphate-activated gamma(3)-subunit gene associated with low glycogen content in pig skeletal muscle and improved meat quality. Genetics 159, 1151-1162.

Ernst, C.W., Robic, A., Yerle, M., Wang, L., and Rothschild, M.F. (1998). Mapping of calpastatin and three microsatellites to porcine chromosome 2q2.1-q2.4. Anim. Genet. 29, 212-215.

Fan, B., Onteru, S.K., Plastow, G.S., and Rothschild, M.F. (2009). Detailed characterization of the porcine MC4R gene in relation to fatness and growth. Anim. Genet. 40, 401-409.

He, J., Watkins, S., and Kelley, D.E. (2001). Skeletal muscle lipid content and oxidative enzyme activity in relation to muscle fiber type in type 2 diabetes and obesity. Diabetes 50, 817-823.

Hernandez-Sanchez, J., Visscher, P., Plastow, G., and Haley, C. (2003). Candidate gene analysis for quantitative traits using the transmission disequilibrium test: the example of the melanocortin 4-receptor in pigs. Genetics 164, 637-644.

Houston, R.D., Cameron, N.D., and Rance, K.A. (2004). A melanocortin-4 receptor (MC4R) polymorphism is associated with performance traits in divergently selected Large White pig populations. Anim. Genet. 35:386-390.

Huang, L.S., Ma, J.W., Ren, J., Ding, N.S., Guo, Y.M., Ai, H.S., Li, L., Zhou, L.H., and Chen, C.Y. (2004). Genetic variations of the porcine PRKAG3 gene in Chinese indigenous pig breeds. Genet. Sel. Evol. 36, 481-486.

Kim, K.S., Larsen, N., Short, T., Plastow, G., and Rothschild, M.F. (2000). A missense variant of the porcine melanocortin-4 receptor (MC4R) gene is associated with fatness, growth, and feed intake traits. Mamm Genome 11, 131-135.

Kim, K.S., Larsen, N.J., and Rothschild, M.F. (2000). Rapid communication: linkage and physical mapping of the porcine melanocortin-4 receptor (MC4R) gene. J. Anim. Sci. 78, 791-792.

Kim, K.S., Thomsen, H., Bastiaansen, J., Nguyen, N. T., Dekkers, J. C., Plastow, G., and Rothschild, M. F. (2004).
Investigation of obesity candidate genes on porcine fat deposition quantitative trait loci regions. Obes. Res. 12, 1981-1994.

Kim, N., Lim, J., Song, M., Kim, O., Park, B., Kim, M., Hwang, I., and Lee, C. (2008). Comparisons of longissimus muscle metabolic enzymes and muscle fiber types in Korean and western pig breeds. Meat Sci. 78, 455-460.

Meidtner, K., Wermter, A.K., Hinney, A., Remschmidt, $\mathrm{H}_{\text {., }}$ Hebebrand, J., and Fries, R. (2006). Association of the melanocortin 4 receptor with feed intake and daily gain in F2 Mangalitsa x Pietrain pigs. Anim. Genet. 37, 245-247.

Meyers, S.N., and Beever, J.E. (2008). Investigating the genetic basis of pork tenderness: genomic analysis of porcine CAST. Anim. Genet. 3, 531-543.

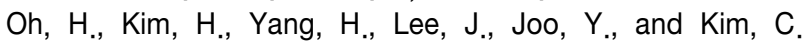
(2008). Comparison of meat quality characteristics between crossbreeds. Korean J. Food Sci. Ani. Resour. 28, 171-180

Rothschild, M.F., Hu, Z.L., and Jiang, Z. (2007). Advances in QTL mapping in pigs. Int. J. Biol. Sci. 3, 192-197.

Short, T.H., Rothschild, M.F., Southwood, O.I., McLaren, D.G., de Vries, A., van der Steen, H., Eckardt, G.R., Tuggle, C.K., Helm, J., Vaske, D.A., Mileham, A.J., and Plastow, G.S. (1997). Effect of the estrogen receptor locus on reproduction and production traits in four commercial pig lines. J. Anim. Sci. 75, 3138-3142.

Switonski, M., Stachowiak, M., Cieslak, J., Bartz, M., and Grzes, M. (2010). Genetics of fat tissue accumulation in pigs: a comparative approach. J. Appl. Genet. 51, 153-168.

Tanner, C.J., Barakat, H.A., Dohm, G.L., Pories, W.J., MacDonald, K.G., Cunningham, P.R., Swanson, M.S., and Houmard, J.A. (2002). Muscle fiber type is associated with obesity and weight loss. Am. J. Physiol. Endocrinol. Metab. 282, E1191-1196.

Tomas, A., Casellas, J., Ramirez, O., Munoz, G., Noguera, J. L., and Sanchez. A. (2006). High amino acid variation in the intracellular domain of the pig prolactin receptor (PRLR) and its relation to ovulation rate and piglet survival traits. J. Anim. Sci. 84, 1991-1998.

Wu, Y.Q., Wu, J.S., Zhao, X.F., Guo, X.L., and Xu, N.Y. (2007). Correlation between porcine CAST gene polymorphism with muscle fiber histological traits and carcass characteristics. Yi. Chuan. 29, 65-69. 